\title{
Letters
}

\section{Racism and health}

\section{Challenge to racism must continue}

Editor-As McKenzie highlights in his editorial, the emphasis to date has been on the role of racism in recruitment and career development. ${ }^{1}$ This must continue despite initiatives and legislation such as the recent Race Relations Amendment Act, as racism still exists in the NHS. ${ }^{2}$ We need to continue to challenge racism not only from our colleagues but also from our patients-zero tolerance is needed. ${ }^{3}$

The importance of racism on health and health care will not diminish owing to increasing migration to the United Kingdom particularly from east European countries. The often hostile reception of the public, media, and some politicians reinforces the negative attitudes that prevail, ${ }^{4}$ and these may manifest through acute and chronic stress to the detriment of the individual. Research on evaluating the mechanism for racism and health outcomes is in early infancy; most studies are being conducted in the United States. We agree with McKenzie that further funding is needed in this area.

The biological models alluded to seem plausible, but before investigating these further substantial research needs to be done first to define, measure, and validate "racism" as an epidemiological variable. Then we need studies to disentangle the effect of racism on health. Urgency and opportunity exist to initiate a national ethnic cohort study within the planned UK Biobank study (www.ukbiobank.ac.uk) to include examination of the effect of racism on health outcomes.

Paramjit S Gill clinical senior lecturer

Department of Primary Care and General Practice, University of Birmingham Medical School, Birmingham B15 2TT

p.s.gill@bham.ac.uk

Raj S Bhopal Bruce and John Usher professor of public health

Department of Community Health Sciences,

University of Edinburgh Medical School,

Edinburgh EH8 9AG

Competing interests: None declared.

1 McKenzie K. Racism and health. BMJ 2003;326:65-6.

2 (11 Jace Relations (Amendment) Act 2000. Available at: Race Relations (Amendment) Act 2000 .
www.legislation.hmso.gov.uk/acts/acts2000/

$20000034 \mathrm{htm}$ (accessed 17 Jan 2003).

3 Wildt de G, Gill P, Chudley S, Heath I. Racism and general practice-time to grasp the nettle. Br J Gen Pract (in press). Modood T, Berthoud R, Lakey J, Nazroo J, Smith P, Virdee S, Beishon S, eds. Ethnic minorities in Britain. Diversity and disadvantage. London: Policy Studies Institute, 1997.

\section{Author's reply}

EDITOR-I agree with Gill and Bhopal that the challenge to racism must continue, and there should be zero tolerance. Racism is complex, and so the response will need to be wide based.

Research has been conducted in the United States and United Kingdom on the nature of racism. There will always be a need to refine measures, but survey tools and instruments are available, supported by a robust literature, that are being used in the United Kingdom.

I support the need for a national ethnic minority cohort study to try to disentangle the effects of racism on health. This should be separate from Biobank. Biobank samples people aged over 45 . It will not be able to address the effect of racism on younger people and pregnant women. It will not address ecological effects. It will not address the changing demographics of areas or populations that may influence the impact of racism on health.

Some may be uncomfortable with the scientific paradigm of Biobank and may call for consultation with black and ethnic minority groups. Oversampling of people of black and ethnic minority groups within Biobank would be useful. If the samples simply reflected the percentage of the ethnic minority populations over 45 in the United Kingdom the study may not have sufficient power for meaningful subgroup analysis. It could be argued that the research would not have delivered equity because it is not as useful to minority groups. It could be argued that it is therefore discriminatory. I am unsure whether this could lead to a challenge under the Race Relations Amendment Act.

However, oversampling in Biobank should not be confused with a proper research effort that addresses the issue of racism and health. Biobank may be useful, but it is too limited to offer the answers required.

Kwame McKenzie senior lecturer in transcultural psychiatry

Department of Psychiatry and Behavioural Sciences, Royal Free and University College Sciences, Royal Free and University
Medical School, London NW3 2PF Medical School, London

Competing interests: None declared.

\section{Australia's Aboriginals suffer} disproportionate burden of ill health

EDIToR-McKenzie has highlighted the association between racism, morbidity and mortality. ${ }^{1}$ I respond as an epidemiologist for Aboriginal health in central Australia.

About 20000 Aboriginal people live in central Australia, most of them in small communities scattered across the vast desert area. Aboriginal Australians have a disproportionate burden of ill health compared with their non-Aboriginal counterparts. Their life expectancy is about 20 years lower, and $58 \%$ of Aboriginals die before the age of $55 .^{2}$ Their morbidity load is far greater than that of non-Aboriginals, and the bulk of morbidity is due to chronic diseases such as diabetes, heart disease, and chronic obstructive airways disease. From birth weight to life expectancy, disparities in health indicators between the two populations are glaring.

Much of the research work in the past has been directed at socioeconomic status, cultural factors, and position in the social hierarchy. Not much attention has been given to racism and its effects on health status. McKenzie's editorial implies that racism may be aetiologically important in the development of illness. ${ }^{3}$ Overt or implicit racial discrimination is recognised to be the underlying cause for poor health status.

Although research based evidence is scant to show that racism being the underlying cause for health inequalities in central Australia, there are some setbacks in the system that may be aggravating the disparity: - Inappropriate responses from health services

- Lack of coordination among various categories of healthcare staff

- Absence of mechanisms for evaluating the effectiveness of services

- Lack of a public health and epidemiological approach

- High turnover of healthcare staff.

These factors may well be the consequences of intrinsic racism in the system. The disturbing health inequalities between Aboriginal and non-Aboriginal population are acknowledged time and again, but no appropriate action seems to be in place to address these problems and reduce the inequity gap. Requisite skills and knowledge to rectify these problems may be lacking among key managerial staff. I hope the above factors are given serious consideration while planning services that would in turn generate effective solutions.

Ruby Kaul epidemiologist

Department of Health and Community Services, PO Box 721, Alice Springs, Northern Territory 0871, Australia

Competing interests: None declared.

1 McKenzie K. Racism and health. BMJ 2003;326:65-6. (11 January.) 
2 Epidemiology Branch. The health and welfare of territorians. Darwin: Territory Health Services, 2001.

Dee CC A multilel a Gee GC. A multilevel analysis of the relationship between health status. Am J Public Health 2002;92:615-23.

4 Winnie MS. Statement of World Health Organization. Durban, September 2001.

\section{Spirituality and clinical care}

\section{Placebo or not-we may never know}

EDITOR-I agree with Culliford that knowing your patients better makes for a better therapeutic relationship. ${ }^{1}$ Often-for example, in terminal care or when physical measures do not have an impact on any disease-being able to relate in "wider" terms can increase the potential for healing. But I disagree with Culliford on the question of methodology.

Most religions and other arenas of spirituality use ritualised gestures, incantations, prayers, symbolism, and rites. Unless you believe that these processes have effects through a perceived extracorporeal being, power, or energy, the effect is presumed to come from within patients themselves. But the placebo effect is inherently based on its own camouflage. Once you know you're taking placebo then the magic is lost.

The entire effect is dependent on your "faith" in the procedure. Although I might deliberately use the placebo effect in my pharmacological treatment of patients, is it not an unethical deceit for me to portray a facade of spirituality for their benefit when I don't believe it myself? If that is true then what is Culliford suggesting? Might it be that my deficiencies as a non-believer translate into deficiencies as a doctor? Perhaps I don't really want an answer to that.

Daniel R Nethercott senior house officer, palliative medicine

Holme Tower, Marie Curie Centre, Penarth,

South Glamorgan CF64 3YR

danielnethercott@hotmail.com

Competing interests: DRN is a practising atheist.

1 Culliford L. Spirituality and clinical care. BMJ 2002;325:1434-5. (21 December.)

\section{Spiritual care based primarily on} happiness is dangerous

EDITOR-Culliford's editorial reflects a resurgent interest in spiritual aspects of healing through discontent with a purely materialistic world view. ${ }^{1}$ Our culture does not believe in a pure scientific reductionist model that says we are made solely of a chemical structure (witness the Princess Diana experience and films such as Sixth Sense and Star Wars). Our experience tells us there is a greater depth to life, and I welcome Culliford's recognition of this as central in healthcare provision. However, a case for spiritual awareness and treatment based primarily on outcomes of happiness and wellbeing is dangerous. Leading patients to believe that spirituality brings happiness may cause upset through disappointment or more seriously propound disregard for spiritual truth-“It doesn't matter what you believe as long as it makes you happy." Of far greater importance is "Is it true or not?"
Consider Christianity as an example. The experience of many is that faith brings a deep joy that surpasses day to day happiness and upset. However, Christianity does not always bring happiness. Christ claimed he was God's son and was crucified for it. Many who followed him since have been martyred for their beliefs, and countless more suffer daily persecution for being called "Christian." Living out the Christian faith in itself is hard work. Therefore it matters whether this faith is based on truth. ${ }^{2}$

The spiritual side of clinical care is important. We should be careful, however, to avoid misleading spiritual platitudes that bring happiness at the expense of truth.

Matt J Hawker senior house officer, ophthalmology Worcestershire Acute Hospitals NHS Trust, Worcester WR5 1DD

mands@freenetname.co.uk

Competing interests: $\mathrm{MH}$ is a Christian.

1 Culliford L. Spirituality and clinical care. $B M$ 2002;325:1434-5. (21 December.)

15:17-19. New International Version.) International Bible Society, 1984.

\section{Spirituality is not everyone's cup of tea} for treating addiction

EDITOR-Culliford's editorial about spirituality in medicine raises some important issues. ${ }^{1}$ In alcohol and drug treatment the spiritual dimension can play a part in recovery. The 12 step model developed by Alcoholics Anonymous has several important therapeutic elements, one of which is promoting the development of spirituality, and the large Project MATCH study of drinking outcomes found 12 step facilitation to be as effective as other forms of psychological treatment. $^{2}$

We recently conducted a questionnaire survey of 60 people attending Narcotics Anonymous groups in the West Midlands. We asked the attenders to rate their level of group attendance and participation, their belief in a higher power, and the amount of time that they devoted to any form of spiritual practice. The results showed that $90 \%$ of the participants had a belief in a power greater than themselves, and on average 50\% allowed time for spiritual practices at least once daily. Linear regression analysis showed that spiritual practices, along with attendance and engagement with the self help groups, were significant predictors of abstinence in this group of substance misusers.

The finding that participants allow themselves some time to engage in spiritual activities every few days is consistent with the work of Finney and Maloney, who found meditation to be an effective means of preventing relapse in this group. ${ }^{3}$ It also links to Geisler's work, which shows that spiritual practices combined with psychosocial treatment are effective aids to misusers in reducing their drug use, ${ }^{4}$ as well as to other work that indicates that prayer and meditation positively influences coping.

We believe, however, that the spiritual dimension is potentially a double edged sword for engagement in self-help groups. Although Alcoholics and Narcotics Anony- mous have over two million members worldwide, few of the people whom we treat use this free and readily available form of long term help. Our clinical experience implies that the perceived "religious" or spiritual element of the process is a strong reason to stop attending self help groups of these organisations, particularly in the early stages.

Ed Day specialist registrar in addiction psychiatry ejday@blueyonder.co.uk

Simon Wilkes psychologist

Alex Copello consultant psychologist

Addictive Behaviours Centre, Birmingham B4 6SX

Competing interests: None declared.

1 Culliford L. Spirituality and clinical care. BMJ 2002;325:1434-5. (21 December.)

2 Project MATCH Research Group. Matching alcoholism treatments to client heterogeneity: Project MATCH post treatment drinking outcomes.J Studies Alcohol 1997;58(1): 7-29.

3 Finney JR, Maloney HN. Empirical studies of Christian prayer: a review of the literature. J Psychol Theol 1985; 13:104-15.

4 Geisler M. Transcendental meditation as a therapeutic tool for drug users. J Clin Psychol 1978;7:235-55.

5 Hjelle L. Transcendental meditation and psychological health. Perception Motor Skills 1974;39:623-8.

\section{National service framework for diabetes leaves questions open}

EDITOR-The much delayed national service framework for diabetes has major implications for primary and secondary care services in England. ${ }^{1}$ Many of its proposals are to be welcomed, but some of them are vague, with little indication of how they can be implemented.

The most serious problem is the absence of identified resources to allow improvements in diabetes care to be implemented effectively. We are informed that there will be some funding for retinal cameras, but no indication is given about how the revenue consequences of major screening programmes will be addressed. We are told that funds for the national service framework will be provided to primary care trusts in the baseline allocation for general medical services, but there is no guarantee that these will be ringfenced. In many areas new monies seem to have already been swallowed up by historical debts.

Much of the focus of the national service framework is on primary care, but diabetes expertise is lacking in many practices. ${ }^{2}$ Developing the necessary skills in primary care will need an educational programme, which will depend on local specialist diabetes services. The Association of British Clinical Diabetologists has already shown deficiencies and lack of resources (especially in numbers of consultants, specialist nurses, dietitians, and podiatrists) in many specialist centres, ${ }^{3}$ so it is hard to see how the necessary support can be provided.

Already there are major medical recruitment problems, with trusts being unable to attract suitable candidates for posts such as consultant diabetologists. Without adequate specialist diabetes services there is a real risk of substandard 
diabetes care in many districts. The resource and staffing consequences of the national service framework need to be addressed urgently, otherwise its impact will be minimal, care overall will not improve, and the morbidity and mortality in the diabetic population will not be reduced.

\section{Richard H Greenwood chairman \\ richard.greenwood@nnuh.nhs.uk \\ K M Shaw honorary treasurer \\ P Winocour honorary secretar \\ Association of British Clinical Diabetologists, \\ London W1P 4HQ}

Competing interests: None declared.

1 Mayor S. Government publishes strategy to improve diabetes care. $B M J$ 2003;326:121. (18 January.)

2 Williams DRR, Baxter H, Airey CM, Ali S, Turner B Diabetes UK funded surveys of the structural provision of primary care diabetes services in the UK. Diabet Med primary care diabetes
2002;19(suppl 4):21-6.

3 Winocour PH, Ainsworth A, Williams DRR. Association of British Clinical Diabetologists (ABCD) survey of secondBritish Clinical Diabetologists (ABCD) survey of secondary care services for diabetes in the UK, 2000. 1. Met
and major findings. Diabet Med 2002;19:327-333.

\section{Cardiovascular risk scores and prescribing in diabetes}

Using risk tables to assess cardiovascular risk in type $\mathbf{2}$ diabetes has drawbacks

Editor-Hall et al describe the use of primary prevention risk tables in type 2 diabetes. ${ }^{1}$ We agree that targeting cardiovascular risk in diabetes is a priority, but their proposals imply an overreliance on risk scores as the sole determinant of cardiovascular risk assessment in diabetes. This approach might lead to withholding treatment in some people whose risk is underestimated by risk scores.

Unfortunately, the decision at what level of cardiovascular risk to start lipid lowering treatment in diabetes is not straightforward. The authors' oversimplistic approach, although convenient, is unscientific and flies in the face of epidemiological evidence which suggests that type 2 diabetes should be regarded as a disease group for secondary rather than primary prevention. ${ }^{2}$

Using the Framingham equation to evaluate cardiovascular risk in diabetes entails caveats. These include a low baseline prevalence of diabetes in the Framingham cohort and the omission from the equation of triglyceride concentration, an important determinant of cardiovascular risk in type 2 diabetes. ${ }^{3}$ The low prevalence of diabetes in the cohort leads to wide confidence intervals in the predicted risk. Thus, in a diabetic man with average risk factors, the upper 95\% confidence interval crosses the $15 \%, 10$ year threshold from the age of 40 onwards. ${ }^{3}$

People with risk scores below a chosen cut-off point may therefore have a higher true risk. The proposals by Hall et al would lead to a rigid prescribing protocol whereby all patients with scores above a threshold (for example, 15\%) would receive treatment, whereas those below would not. Furthermore, an overemphasis on the risk score might be at the expense of ignoring other key factors not represented by the Framing- ham risk equation, such as ethnic group, family history, microalbuminuria, and triglyceride concentration.

Jamie Smith specialist registrar jamie.smith@virgin.net

Roger Corrall consultant physician

Department of Diabetes and Endocrinology, Bristol Royal Infirmary, Bristol BS2 8HW

Competing interests: None declared.

1 Hall LML, Jung RT, Leese GP. Controlled trial of effect of documented cardiovascular risk scores on prescribing. BMJ 2003;326:251-2. (1 February.)

2 Haffner SM, Lehto S, Ronnemaa T, Pyorala K, Laako M Mortality from coronary heart disease in subjects with type 2 diabetes and in nondiabetic subjects with and withou prior myocardial infarction. $N$ Engl J Med 1998;339: $229-34$.

Yeo WW, Yeo KR. Predicting CHD risk in patients with diabetes mellitus. Diabet Med 2001;18:341-344.

\section{Authors' reply}

EDITOR-The purpose of our paper was to identify whether there was clinical value in having cardiovascular risk scores. We wanted to identify whether having an integrated single score of macrovascular cardiovascular risk highlights to clinicians that a clinical issue needs addressing, which influences their prescribing habits. Our paper indicates that this is the case and that in the setting of a busy clinic having to assess a multitude of individual risk factors may result in cardiovascular risk being overlooked. Having established that an integrated score is useful to practising clinicians, the next challenge is to identify an appropriate risk score to use.

Smith and Corrall correctly indicate that the New Zealand risk score, and others based on Framingham, all underestimate the cardiovascular risk in diabetes, although data from Tayside indicate that this is probably not to the extent suggested by Haffner et al. ${ }^{12}$ Also, the level of risk chosen to start treatment is an arbitrary cut-off point which can be adjusted-for example, to $15 \%$ from $20 \%$-if thought desirable. The real answer is to define the epidemiology of cardiovascular risk in diabetes more accurately so that more accurate tables can be developed.

Graham P Leese consultant in diabetes graham.leese@tuht.scot.nhs.uk

Lesley Hall medical student

Roland Jung consultant

Ninewells Hospital, Dundee DD19SY

Competing interests: None declared.

1 Evans JM, Wang J, Morris AD. Comparison of cardiovascular risk between patients with type 2 diabetes and thos who had had a myocardial infarction: cohort studies. BMJ 2002;324:939-42.

2 Haffner SM, Lehto S, Ronnemaa T, Pyorala K, Laako M. Mortality from coronary heart disease in subjects with type diabetes and in nondiabetic subjects with and withou prior myocardial infarction. NEngl J Med 1998;339:229-34

\section{Failing to bark and barking}

EDITOR-Le Fanu's Sherlock Holmes style case of the missing data and dog that failed to bark had amusing elements but also misunderstandings, errors, and accusations of concealment, implying bad faith.
- Twenty one countries took part in the World Health Organization's monitoring trends and determinants in cardiovascular disease (MONICA) project, not 27.

- MONICA had set out to validate and explain such trends. Our 1999 paper on trend results was big news internationally, including the $B M J{ }^{2}$ but apparently Le Fanu missed it.

- Mortality data are freely downloadable from the World Health Organization. The dearth of publications on mortality trends in scientific journals is not from conspiracy. Any novice can have a go, so editors and reviewers are overburdened with enthusiasts trying to prove things badly. Works of scholarship may have an uphill fight for publication because routine mortality statistics are considered trivial and unscientific compared with laboratory studies.

- Americans did not study immigrants just from Japan. Studies go back 55 years, classically contrasting New York's Italians with its Jews, and Irish and Norwegians in the United States with brothers in the home country, more recently focusing on Hispanics and newer ethnic groups. Disease rates are easier to study with first generation migrants, place of birth providing a census denominator, than later on.

- Smoking shows all or none differences in one population, where diet has historically been more uniform. Diet differs greatly between populations, thereby determining a population's susceptibility to cardiovascular disease and also to specific cancers. The cholesterol story is well established, but diet is now known to contain more varied contributors to coronary risk than dairy fats alone.

- Le Fanu's unoriginal suggestion that coronary disease has an infective origin would not in itself explain why it took 10 years to cross the Atlantic as an epidemic, and half a century to reach eastern Europe. Lifestyle fits better. Existing explanations for disease trends must give way to better ones, but they must be more specific than that.

Le Fanu claimed in the Sunday Telegraph Magazine in 2000 that I published research that I knew to be false, that was nonsense and quackery, and that I was a danger to the public. ${ }^{3}$ Although now apparently running with the fox as well as hunting with the hounds, by characterising MONICA collaborators as not barking he claims the opposite role for himself.

Hugh Tunstall-Pedoe professor of cardiovascular epidemiology

Cardiovascular Epidemiology Unit, University of Dundee, Ninewells Hospital, Dundee DD1 9SY h.tunstallpedoe@dundee.ac.uk

Competing interests: HT-P was a project author and principal investigator in the WHO MONICA project.

A longer version of this letter complete with references is available at bmj.com/cgi/eletters $325 / 7378 / 1490 \# 30160$ 1 Le Fanu J. The case of the missing data. BMJ 2002;
325:1490-3. (21 December.)
2 Kmietowicz Z. Heart disease mortality declining with fewer
and less deadly attacks. BMJ 1999;318:1307.
3 Le Fanu J. Scientists who should carry a health warning. Sunday Telegraph Magazine 2000 (July 9). 


\section{Competing interests}

\section{Consent was not obtained}

EDITOR-So, the editor of the $B M J$ is happy to coauthor research involving undeclared deception of subjects and publish it in his journal. $^{1}$ Three hundred readers were unwitting dupes. They took part without being informed what the real object of the exercise was, no informed consent here, at least not by the standard of being willing to show the subject the research protocol.

This sort of research violates Kant's categorical imperative-act as if this were a universal principle. It seeks payment in a coin that it debases for others. ${ }^{2} B M$ J readers should be warned: next time a researcher contacts you for an opinion, it is probably a hoax.

What is ironic about the paper is that the results have meaning only if the respondents were more honest than the authors. My warning to researchers is as follows: if you deceive your subjects what right have you to expect they will not do the same to you?

Stephen J Senn professor of pharmaceutical and heath statistics

University College London, London WC1E 6BT stephens@public-health.ucl.ac.uk

Competing interests: SJS is a consultant to the pharmaceutical industry and an academic. His career is therefore furthered by publication.

1 Chaudhry S, Schroter S, Smith R, Morris J. Does declaration of competing interests affect readers' perceptions? A randomised trial. BMJ 2002;325:1391-2. (14 December) 2 Senn SJ. The ignoble lie. J Clin Epidemiol 1992;45:1338-9. 3 Senn SJ. Are placebo run-ins justified? BMJ 1997;314:1191.

\section{Problem is greater than editorial indicates}

EDITOR-The BMJ should be congratulated for its efforts to avoid bias in the reporting of scientific work. ${ }^{1}$ Asking editors and authors explicitly to state competing interests reduces the likelihood of bias. As Smith rightly says, however, we still have some way to go to the fully transparent world. Much of the discussion of conflict of interest may leave the impression that the problem lies in commercial sponsorship, in particular from the pharmaceutical and tobacco industries.

The problem may be more widespread, however. Could researchers in a public health institute be influenced by political pressures when the institute is financed directly by the health ministry? Will the pressure become stronger when the research institute is placed within the ministry? Can researchers who receive honoraria for advising government and courts on tobacco issues be influenced by the fees they receive? If researchers can be influenced by commercial sponsorship, and the evidence here is convincing, why should researchers be immune to influence from other sponsors? Nevertheless, it is not unusual that research financed by government and other non-commercial sources is presented without warning the reader that there is a potential conflict of interest.

My point is not that bias from commercial sponsorship should be belittled but rather to emphasise that the problem is greater than Smith's editorial may indicate.
Policies to avoid bias in the conduct and reporting of research should be guided by scientific principles, not by moralism or prejudice.

Ivar S Kristiansen senior researcher

Institute of Public Health, University of Southern Denmark, DK-5000 Odense, Denmark ivarsk@c2i.net

Competing interests: ISK has received salary and honoraria from several public institutions and honoraria from several pharmaceutical firms. He has not received honoraria from the tobacco industry.

1 Smith R. Making progress with competing interests. BMJ 2002:325:1375-6.(14 December.)

\section{It's my journal, and I'll write if I want to} EDITOR-

Richard and colleagues just walked

Through the door

Like a king with his court

He says he's had a great idea

And surely to publish they ought.

Sorry, my muse left on holiday after that. Please feel free to add some more verses. Like other respondents, I applaud the BMJ's crusade to enlighten readers about the issues of conflicting interests. ${ }^{1}$ The paper by Chaudhry et al should surely have been submitted to another journal, or if not then someone else should have it. ${ }^{2}$ The BMJ's peer journals are not the $B M J$ itself.

Could we be informed as to how long the paper was out at the reviewers and how quickly it got accepted in its final version? It was published within six weeks of acceptance. That's nice. I have had work published in the $B M J$, on one occasion after the manuscript (and I am quoting directly from the correspondence at the time) "lay in the top drawer" of a staff statistician's desk for six months. I doubt that would ever happen to an editor's paper.

These are small points but if the BMJ's crusade is to be credible and successful, inhouse guidelines about staff submissions should be torn up and replaced by a rule that $B M J$ related work is only submitted elsewhere.

Jonathan O'B Hourihane senior lecturer, infection, inflammation, and repair

Mailpoint 218, Southampton University Hospitals NHS Trust, Southampton SO16 6YD j.hourihane@soton.ac.uk

Competing interests: None declared.

1 Smith R. Making progress with competing interests. BM 2002;325:1375-6. (14 December.)

2 Chaudhry S, Schroter S, Smith R, Morris J. Does declaration of competing interests affect readers perceptions? randomised trial. BMJ 2002;325:1391-2. (14 December.)

\section{Authors' reply}

EDITOR-Medical researchers like Senn are often very concerned about minor deception, but its use is common in the social sciences. We at the $B M J$ have debated the use of deception with our ethics committee, and it sees no problem so long as the deception is minor, the study would be hard or impossible to do in any other way, and participants are informed afterwards.

We agree with Kristiansen that all forms of financial-and non-financial-conflict of interest are important. Our anxiety is not only about commercial sponsorship, and we have had examples in Britain of the government trying to interfere with the publication of research. We disagree, however, with the implication in Kristiansen's letter that the use of scientific principles can avoid the influence of conflicts of interest. The evidence suggests otherwise.

There are strong arguments against editors publishing original research in their own journals and egregious examplesfrom Cyril Burt and Hans Eysenck-of editors publishing highly dubious research in their own journals. Nevertheless, it makes sense for editors to try to publish in their own journals when the research is conducted on readers, authors, or reviewers associated with the journals and the results influence the policies of the journals.

That was the case with this research, and we do have a declared method of reviewing research submitted to the $B M J$ by the editorial staff that excludes editors employed by the journal at every stage. And we have had several papers rejected.

Richard Smith editor

Sara Schroter research fellow $B M J$, London WC1H 9JR

\section{Barriers to managing heart failure in primary care}

Heart failure clinics provide crucial link between primary and secondary care

EDITOR-Fuat et al surveyed attitudes towards managing heart failure in general practice. ${ }^{1}$ Points of particular note included difficulties in assessing subtle early signs of heart failure, difficulties in interpreting echocardiography reports, and concerns about the number of drugs recommended for patients with heart failure.

This study further strengthens the case for specialist heart failure clinics as outlined in the national service framework for coronary heart disease. ${ }^{2}$ Such clinics have a multidisciplinary team consisting of physicians (specialist and primary care), specialist nurses, and cardiac technicians, and these teams facilitate a coordinated approach to diagnosing, assessing, and managing heart failure. Objective evidence of cardiac dysfunction may be obtained and interpreted by a cardiologist, with the subsequent formulation of a treatment strategy.

We believe that this is preferable to open access echocardiography services, with the difficulties in interpretation highlighted by Fuat et al. ${ }^{1}$ Specialist dedicated nursing provides a crucial bridge between hospital and community care, allowing continued clinical assessment and appropriate titration of drug treatment, as well as continued patient education. Such nursing has been associated with a significant reduction in hospital readmission for heart failure. ${ }^{3}$ Widespread awareness of current treatment guidelines seems to be lacking in primary care; dedicated nursing services 
can be instrumental in implementing guidelines.

Heart failure is thought to invariably affect elderly people. This is simply not true. Clearly the disease becomes more prevalent with age, but diagnosis is delayed in many young patients with dilated cardiomyopathy because of this perception.

Heart failure has a high prevalence and is associated with a terrible prognosis, despite the availability of evidence based treatments. General practitioners are at the sharp end of an escalating problem, and specialist clinics provide invaluable support for the growing burden of chronic heart failure.

Russell C Davis consultant cardiologist

R.C.Davis@bham.ac.uk

Gurbir Bhatia research fellow

Michael Sosin research fellow

Jane Stubley senior heart failure specialist nurse

Sandwell and West Birmingham NHS Trust,

West Bromwich B71 4HJ

Competing interests: None declared.

1 Fuat A, Hungin AP, Murphy JJ. Barriers to accurate diagnosis and effective management of heart failure in primary care: qualitative study. BMJ 2003;326:196-201. (25 January.) 2 Department of Health. The national service framework for coronary heart disease. London: Stationery Office, 2000.

3 Blue L, Lang E, McMurray JV, Davie AP, McDonagh TA, Murdoch DR, et al. Randomised controlled trial of specialist nurse intervention in heart failure. BMJ 2001;323:715-8.

\section{Previous study revealed other factors to} be important in management

Editor-Fuat et al describe an important problem in their article on diagnosing and managing heart failure in primary care. ${ }^{1} \mathrm{We}$ investigated this same issue by semistructured interviews with individual general practitioners. This investigation undertaken in 1998 identified many themes that were common to Fuat et al's study using focus groups of general practitioners. ${ }^{2}$ However, two important themes we identified are absent in this later study.

The first is that discussion of patients with "suspected heart failure" was very difficult, general practitioners more readily identifying with symptom based scenarios, such as managing breathless patients.

The second theme was "therapeutic trials." Most general practitioners described difficulties in distinguishing between chronic obstructive pulmonary disease and heart failure. Several general practitioners described using bronchodilators or diuretics to determine which could alleviate symptoms, arriving at a symptomatic rather than pathophysiological diagnosis.

The general practitioners we interviewed were aware of the benefits of angiotensin converting enzyme inhibitors, but symptom control seemed to be the focus of management in many cases. These additional factors, which featured highly in the thinking of some practitioners, should be taken account of in the design of any future interventions to improve the management of heart failure in primary care.

Mark F Lambert director of public health Gateshead Primary Care Trust, Gateshead NE11 0SR

mark.lambert@ghpct.nhs.uk

Ian $\mathbf{S}$ Watt professor of primary and community care University of York, York YO10 5DD
Competing interests: None declared.

1 Fuat A, Hungin AP, Murphy JJ. Barriers to accurate diagnosis and effective management of heart failure in primar care: qualitative study. BMJ 2003;326:196-201. (25 January) Lambert MF, Wat IS, Woodhouse AM, Balmer S, Robinson MR. The need for a diagnostic approach in the development of guideline implementation strategiesqualitative study. Br J Clin Gov 2002;7:255-60.

\section{Congestion charging}

\section{Walking classes also need road space} reallocation

EDITOR-We welcome Roberts's editorial, making the health case for the London congestion charge, ${ }^{1}$ particularly as the revenue is required to be spent on transport. We agree that physically active transport such as walking and cycling is likely to increase. This must be monitored adequately, with attention given to changes in activity levels ${ }^{2}$ and broken down by sociodemographic groups, to assess the impacts on health and inequalities.

Other potential effects of congestion charging include improvement in access for emergency vehicles. However, not all are positive: the impact of the policy will depend on which complementary measures are introduced at the same time.

Firstly, we disagree that less car travel will result in fewer crashes; this impact is difficult to predict. ${ }^{3}$ It depends whether journey times are shorter because of less time queuing at junctions or because of higher speeds. If traffic reduction is greater than was predicted, travel speeds may become substantially faster. While shorter journey times could reduce exposure to the risk of collisions, higher speeds could increase the risk by a greater amount

Secondly, congestion charging alone could adversely affect equity: road space vacated by people who are deterred by the charge could be occupied by the wealthy, who are less price sensitive. ${ }^{4}$

Both effects can be effectively combated by simultaneously introducing measures to reallocate road space and giving priority to buses, preferential access to disabled drivers, and effective protection to cyclists and pedestrians. ${ }^{4}$ This is largely true of the London congestion charge, but it is important to consider when other towns and cities follow suit.

Even London has been timid about pedestrianising road space-Soho and Covent Garden seem ideal candidates. Experience shows that whereas such schemes tend to be initially opposed by local businesses, once the schemes are implemented they benefit economically.

Michael Joffe consultan

Department of Epidemiology and Public Health, Imperial College Faculty of Medicine, London W2 1PF

m.joffe@imperial.ac.uk

Jennifer Mindell deputy director

London Health Observatory, London W1G 0AN

Competing interests: None declared.

1 Roberts I. Congestion charging and the walking classes BMJ 2003;326:345-6. (15 February.)
2 Joffe M, Mindell J. A framework for the evidence base to support Health Impact Assessment. J Epidemiol Community support Health Impact

Mindell J Quentification of health impacts of air qualiy (hir quality and

4 Joffe M, Garnett T, Mindell J. Mapping the links-project evidence base for health impact assessments. http:/

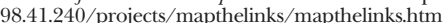
(accessed 1 Apr 2003).

\section{Political polemics are masquerading as} science

EDITOR-Roberts in his editorial on congestion charging is wrong in almost all of his assertions. ${ }^{1}$ The number of cars on the road in central London has remained stable over the past 30 years until it fell by $18 \%$ last year (Transport for London statistics). Slow journey times and congestion are due to more people working in central London and poor road management.

Roberts acknowledges that the vulnerable groups are pedestrians (10-18 times the accident rate of car drivers per $2 \mathrm{~km}$ journey) and cyclists (13 times the accident rate per $2 \mathrm{~km}$ journey), yet he thinks that increasing the size of both of these vulnerable groups by encouraging people to walk or cycle will decrease the number of accidents. Statistical nonsense.

It is generally agreed that the only pollutant to constitute a health hazard at current levels is a small particle emission. How can moving from clean petrol driven cars to dirty diesel buses (buses do not have to conform to any emission standards) help this?

Since there are only about 16 state schools within the congestion charge zone it is absurd to suggest it is going to make mothers happy to allow their children to walk to school throughout the country.

To compare Ken Livingstone to Edwin Chadwick is particularly absurd. Chadwick's plans for sanitation were drawn up at the request of parliament and largely implemented without opposition. He is remembered for his controversial Poor Law Act of 1834, which confined the poor to institutions where families were separated and deliberately subjected to discomfort "to punish them for their indolence." There may be a case for congestion charges but it is not on the grounds of improving health or safety. I cannot believe that this editorial was critically reviewed before publication.

Stanley Feldman professor

28 Moore Street, London SW3 2QW

Competing interests: None declared.

Roberts I. Congestion charging and the walking classes. BMJ 2003;326:345-6. (15 February.)

\section{bimj.com}

Letters appearing here are an edited selection of rapid responses originally posted on bmj.com

We ask for all letters to the editor to be submitted as rapid responses via bmj.com

For advice see: bmj.com/rapidresponses 